\title{
A Study on Raised Serum LDH Level in Acute Intestinal Obstruction - A Marker of Bowel Gangrene
}

\author{
Anantha Kumar Nateson ${ }^{\oplus 1}$, Suresh Nayak Basavanayak ${ }^{\circledR 2}$, Sudarsan Srikanth ${ }^{\oplus 3}$ \\ ${ }^{1}$ Associate Professor, Department of Surgery, Sambhram Institute of Medical Sciences and Research, BEML Nagar, Kolar Gold Fields, Karnataka, India, ${ }^{2}$ Professor \& \\ Head, Department of Physiology, Sambhram Institute of Medical Sciences and Research, BEML Nagar, Kolar Gold Fields, Karnataka, India, ${ }^{3}$ Senior Resident, \\ Department of Surgery, MVJ Medical College and Research Hospital, Kolathur, Karnataka, India.
}

\section{Abstract}

Background: Bowel gangrene is a major abdominal catastrophe associated with high mortality rate. Intestinal obstruction accounts for $20 \%$ of all surgical emergencies around the world. The present study aims to estimate the LDH levels in patients with acute intestinal obstruction and correlate with bowel viability. Subjects and Methods: In this study, the estimation of serum LDH was conducted in 45 cases of acute intestinal obstruction who were admitted in surgical wards. After fulfilling the inclusion and exclusion criteria the study subjects were recruited. All the cases were thoroughly examined. Time of presentation and onset of symptoms were noted. Under aseptic conditions, $3 \mathrm{ml}$ venous blood samples were collected from the study subjects, centrifuged at $3000 \mathrm{rpm}$ and separated serum sample was used for the estimation of lactate dehydrogenase (LDH) and the estimated value of serum LDH is compared with the viability of the bowel intra operatively. Results: The total number of patients presented with obstruction is 45 out of which 25 were found to have elevated LDH which is about $55.56 \%$. Out of 25 patients presented with elevated LDH, 20 patients found to have gangrenous bowel. $60 \%$ presented with abdominal pain and $40 \%$ had irreducible swelling. Most commonly associated symptoms are vomiting (84\%) followed by abdominal distension (40\%), obstipation (36\%), pyrexia (24\%), blood in stools (8\%) and diarrhoea (4\%). Per rectal examination showed $76 \%$ had normal faecal staining, $12 \%$ blood stained faeces and $8 \%$ empty. Complications observed were anastomotic leak $8 \%$, wound infection 16\%, wound gaping $8 \%$, burst abdomen $8 \%$. Conclusion: The present study results indicate that ischemic changes in any part of the bowel can cause elevation in the serum levels of LDH and a higher value of $>1000 \mathrm{IU} / \mathrm{L}$ strongly indicates an underlying gangrenous change. It is a less invasive, cost effective and easily available diagnostic tool to diagnose bowel ischemia/gangrene. Hence it is more useful in centres where the diagnostic facilities are limited.

Keywords: Lactate Dehydrogenase, Bowel Gangrene, Abdominal Pain

Corresponding Author: Suresh Nayak Basavanayak, Professor \& Head, Department of Physiology, Sambhram Institute of Medical Sciences and Research, BEML Nagar, Kolar Gold Fields, Karnataka, India.

E-mail: drbsnayak9106@gmail.com

Received: 29 March 2020

Revised: 24 April 2020

Accepted: 02 May 2020

Published: 29 May 2020

\section{Introduction}

Bowel gangrene is a major abdominal catastrophe associated with high mortality rate. This increased mortality is attributed to difficulty in diagnosing the condition early, the late presentation of the patient to the hospital and non-availability of precised diagnostic tool for assessing bowel gangrene. ${ }^{[1,2]}$

Intestinal obstruction accounts for $20 \%$ of all surgical emergencies around the world. Intestinal obstruction can result from variety of causes. When strangulation superimposes and blood supply to the bowel is compromised, it may lead to bowel gangrene. ${ }^{[3]}$ The most common cause of bowel gangrene secondary to mechanical obstruction is strangulated hernia in India and post-operative adhesions in developed countries.

Lactate dehydrogenase is an enzyme found abundant in intestinal mucosa, transfers hydrogen using NAD+ as hydrogen acceptor thus catalyzing the oxidation of Lactate to pyruvate. LDH activity is present in all the cells of the body predominantly in cytoplasm of the cell and when the intestinal mucosa undergoes tissue hypoxia/ischemia, it is released into the serum and its serum level increases. ${ }^{[4,5]}$ Gut hypoxia causes anaerobic metabolism. The liver receives more lactate from the portal vein. Initially, this is oxidized or converted to glucose by the periportal hepatocytes. Bacterial translocation and profound fluid shifts contribute to circulatory collapse. Global oxygen delivery falls. Endogenous catecholamine release attempts to support the circulation but will 
also increase glycolysis and lactate formation. As shock develops hepatic blood flow falls and intracellular acidosis inhibits gluconeogenesis from lactate. The liver produces rather than clears lactate. Intestinal bacteria metabolize glucose and carbohydrate to D-lactate. This is only slowly metabolized by human LDH and contributes to the escalating lactic acidosis. [6] The present study aims to estimate the LDH levels in patients with acute intestinal obstruction and correlate with bowel viability.

\section{Subjects and Methods}

This study was conducted at Department of General Surgery, Coimbatore Medical College Hospital, Coimbatore, Tamilnadu, India from September 2014 to August 2015. In this study, the estimation of serum LDH was conducted in 45 cases of acute intestinal obstruction who were admitted in surgical wards. LDH was estimated in all the cases preoperatively on the day of admission. Patients presenting with features of acute intestinal obstruction, patients with irreducible inguinal/femoral hernia, patients with features of intestinal obstruction diagnosed preoperatively as a case of SMA/SMV occlusion are included and patients $<18$ years and $>80$ years, pregnant women and psychiatric patients were excluded from the study. After fulfilling the inclusion and exclusion criteria the study subjects were recruited. All the cases were thoroughly examined. Time of presentation and onset of symptoms were noted. The study has been approved by the institutional ethics committee and informed consent was obtained from all the study subjects.

Under aseptic conditions, $3 \mathrm{ml}$ venous blood samples were collected from the study subjects, centrifuged at $3000 \mathrm{rpm}$ and separated serum sample was used for the estimation of lactate dehydrogenase (LDH) and the estimated value of serum LDH is compared with the viability of the bowel intra operatively.

\section{Results}

The total number of patients presented with obstruction is 45 out of which 25 were found to have elevated LDH which is about $55.56 \%$. Out of 25 patients presented with elevated $\mathrm{LDH}, 20$ patients found to have gangrenous bowel. The age incidence in this study was between 19 yrs to 80 yrs.

Males are predominantly affected with male $86 \%$ and female $14 \%$.

Chief complaints: Most commonly presented with abdominal pain $60 \%$ and irreducible swelling $40 \%$.

Duration of symptoms: $44 \%$ of patients presented to the hospital $>48$ hours of onset of symptoms, $28 \%$ in 24 to 48 hours and $28 \%$ in $<24$ hours.

\begin{tabular}{llll}
\hline Table 1: Age incidence in the study subjects & \\
\hline Age & $\begin{array}{l}\text { No. of } \\
\text { patients } \\
\text { with } \\
\text { obstruction }\end{array}$ & $\begin{array}{l}\text { No. of } \\
\text { patients } \\
\text { with } \\
\text { elevated } \\
\text { LDH }\end{array}$ & $\begin{array}{l}\text { No. of patients } \\
\text { with Gan- } \\
\text { grenous } \\
\text { Bowel }\end{array}$ \\
\hline $19-30$ & 7 & 4 & 2 \\
$31-50$ & 23 & 14 & 10 \\
\hline $51-70$ & 12 & 6 & 6 \\
$71-80$ & 3 & 2 & 2 \\
\hline Total & 45 & 25 & 20 \\
\hline
\end{tabular}

Associated Symptoms and Signs: Most commonly pain associated with vomiting $84 \%$ followed by abdominal distension $40 \%$, obstipation $36 \%$, pyrexia $24 \%$, blood in stools $8 \%$, diarrhoea $4 \%$.

Associated Factors: Most commonly associated factor out of 25 cases with gangrene is smoking 64\%, alcohol 14\%, hypertension $28 \%$, diabetes mellitus $30 \%$.

Per Rectal Examination: 76\% normal faecal staining, 12\% blood stained faeces, $8 \%$ empty.

X-ray abdomen: Done in all patients. $36 \%$ no significant finding, 40\% dilated bowel loops, $24 \%$ air fluid levels, $4 \%$ air under diaphragm.

\section{LDH levels in study subjects:}

Among 45 patients presented with obstruction 20 patients had LDH level between 50 to 200 and all the 20 patients had normal bowel viability and 3 patients had LDH level between 200 to 400 and all the three patients had normal bowel viability. 4 Patients had LDH level between 400 to 800 and two of them had normal bowel viability and two others had bowel gangrene. 8 Patients had LDH level between 800 to 1200 and all of them had bowel gangrene. 10 Patients had LDH level more than 1200 and all of them had bowel gangrene.

\section{Complications:}

Anastomotic leak $8 \%$, wound infection $16 \%$, wound gaping $8 \%$, burst abdomen $8 \%$.

\section{Post-operative follow up:}

All the patients were given broad spectrum antibiotics and injection metronidazle for 7 days. 5 patients developed wound infection and were treated according to the wound culture and sensitivity. Daily examination of laparotomy wound and drain site done. All patients catheterised until adequate output maintained and continuous RT aspiration done until $<20$ $\mathrm{ml}$ aspirated for 24 hours. One patient required mechanical ventillatory support and extubated on first POD. The patients with systemic hypertension and diabetes mellitus managed accordingly. 


\begin{tabular}{|c|c|c|c|}
\hline Etiology & No. cases & $\begin{array}{l}\text { No. cases } \\
\text { with } \\
\text { increased } \\
\text { LDH }\end{array}$ & $\begin{array}{l}\text { No. cases } \\
\text { with Gan- } \\
\text { grenous } \\
\text { Bowel }\end{array}$ \\
\hline $\begin{array}{l}\text { Adhesive } \\
\text { intestinal } \\
\text { obstruction }\end{array}$ & 23 & 9 & 7 \\
\hline $\begin{array}{l}\text { Strangulated } \\
\text { inguinal } \\
\text { hernia }\end{array}$ & 8 & 6 & 4 \\
\hline $\begin{array}{l}\text { SMA occlu- } \\
\text { sion }\end{array}$ & 6 & 4 & 4 \\
\hline $\begin{array}{l}\text { Post- } \\
\text { operative } \\
\text { constriction } \\
\text { bands }\end{array}$ & 5 & 3 & 2 \\
\hline $\begin{array}{l}\text { Strangulated } \\
\text { femoral her- } \\
\text { nia }\end{array}$ & 2 & 2 & 2 \\
\hline $\begin{array}{l}\text { SMV occlu- } \\
\text { sion }\end{array}$ & 1 & 1 & 1 \\
\hline Total & 45 & 25 & 20 \\
\hline
\end{tabular}

\section{Discussion}

Gangrenous bowel recognized as a potential cause of mortality. It occurs due to various causes. The level of lactate dehydrogenase elevates during an inflammatory process due to cellular function alterations and damage to the cells. The cell membrane permeability becomes altered due to ischemia and hypoxia and LDH is released into the circulation. The normal level of serum LDH is 50 to $200 \mathrm{IU} / \mathrm{L}$. Out of 45 patients 25 patients had elevated serum LDH which is about $55.56 \%$ and among those 25 patients, 20 patients found to have bowel gangrene which is about $80 \%$. In our study the mean value of elevated serum LDH in bowel gangrene patients is $1037 \mathrm{IU} / \mathrm{L}$.

The youngest patient is 19 years old who presented with postoperative constriction band causing gangrene of ileum. The oldest patient is 80 years old and presented with strangulated inguinal hernia. The peak incidence is in the fifth decade with $33.3 \%$ and the most common cause of obstruction is found to be adhesive intestinal bands which are about $49 \%$ and among those 22 patients 8 patients had elevated LDH which is about $36.4 \%$. Among those 8 patients, 6 patients found to have gangrene intraoperatively which is about $75 \% .8$ patients presented with strangulated hernia which is about $17.8 \%$ and among those 8 patients, 6 patients had elevated serum LDH which is about $75 \%$.

And among those 6 patients, 4 patients were found to have gangrenous bowel which is $66.7 \%$. 6 patients were found to have SMA occlusion and 4 patients among them were found to have elevated serum LDH. All the 4 SMA occlusion patients with elevated serum $\mathrm{LDH}$ were found to have gangrenous bowel, which is $100 \%$. 4 patients were found to have postoperative constriction band among whom 2 patients had elevated serum LDH which is 50\%. Among those 2 patients with elevated serum $\mathrm{LDH}$, one patient had bowel gangrene which is $50 \%$.

2 patients presented with strangulated femoral hernia and both of them had elevated LDH and gangrene. The incidence of bowel obstruction and gangrene is more common in males $(72 \%)$ than females $(28 \%)$. Strangulated hernia occurs commonly in males than females due to increased physical activities and strenuous efforts. Mesenteric vessel occlusion is also common in males than females may be due to thrombogenic factors like smoking and alcoholism.

The delayed time of presentation shown to influence the morbidity and mortality. Increased morbidity is seen in gangrene patients due to undue delay in presentation due to prolonged exposure of bacterial toxins leading to the onset of septicemia. Previously, an elevated level of serum LDH is considered as a indicator to assess the time of onset of myocardial infarction. Recently, an elevated level of serum $\mathrm{LDH}$ is visualized in patients who had bowel gangrene.

According to Muchas, an elevated level of LDH is found in $86 \%$ of patients who had bowel gangrene. [5] "Lactate dehydrogenase is one of the markers of intestinal ischemia". Thompson. ${ }^{[7]}$ A study conducted by Lange. H, Jackel. $\mathrm{R}$ revealed an inference of $100 \%$ sensitivity and $42 \%$ specificity for increased LDH in patients presenting with acute abdomen who later are found to have intestinal ischemia and gangrene. ${ }^{[8]}$

\section{Conclusion}

From this study it is evident that ischemic changes in any part of the bowel can cause elevation in the serum levels of LDH and a higher value of $>1000$ IU/L strongly indicates an underlying gangrenous change. It is a less invasive, cost effective and easily available diagnostic tool to diagnose bowel ischemia/gangrene. Hence it is more useful in centres where the diagnostic facilities are limited.

The pre-operative estimation of serum LDH levels in patients presenting with features of acute intestinal obstruction helps in identifying the patients who undergo intestinal ischemia and gangrene at the earliest which makes an early intervention possible and helps in reducing the morbidity and mortality due to bowel gangrene. Early diagnosis and early intervention is the key to reduce the mortality rate due to bowel gangrene. Further studies with large sample size is recommended. 


\section{References}

1. Sun DL. Accuracy of Using Serum D-Dimer for Diagnosis of Acute Intestinal Ischaemia: A Meta- Analysis. Johannes Mayr Med. 2017;96:13-13.

2. $\mathrm{D} \mathrm{MB}, \mathrm{K} \mathrm{A}, \mathrm{S} \mathrm{ARG}, \mathrm{R} \mathrm{HH}, \mathrm{H} \mathrm{AV}$, Ali MA, et al. The role of pre operative serum $\mathrm{LDH}$ and D-dimers in predicting intestinal necrosis. Int Surg J. 2019;6(6):21392139. Available from: https://dx.doi.org/10.18203/2349-2902. isj20192381. doi:10.18203/2349-2902.isj20192381.

3. Ashok R, Sumathi P, Tamilselvan N. A Study on Raised Serum LDH Level in Acute Intestinal Obstruction- A Marker of Bowel Gangrene. IOSR J Dent Med Sci. 2016;15(12):8-10.

4. Klein R, Nagy O, Tóthová C, Chovanová F. Clinical and Diagnostic Significance of Lactate Dehydrogenase and Its Isoenzymes in Animals. Vet Med Int. 2020;2020:53464835346483. doi:10.1155/2020/5346483.

5. Mucha P. Small Intestinal Obstruction. Surg Clin North Am. 1987;67(3):597-620. Available from: https://dx.doi.org/10.1016/s0039-6109(16)44234-9. doi:10.1016/s0039-6109(16)44234-9.

6. Phypers B, Pierce JT. Lactate physiology in health and disease. Cont Edu Anaesth Cri Care Pain. 2006;6(3):128132. Available from: https://dx.doi.org/10.1093/bjaceaccp/ mk1018. doi:10.1093/bjaceaccp/mk1018.

7. Thompson JS, Bragg LE, West WW. Serum Enzyme Levels During Intestinal Ischemia. Ann Surg. 1990;211(3):369369. Available from: https://dx.doi.org/10.1097/00000658 199003000-00009. doi:10.1097/00000658-199003000-00009.

8. Lange H, Jackel R. Usefulness of plasma lactate dehydrogenase conc in the diagnosis of acute abdominal disease. Eur J Surg. 1994;160:381-384.

Copyright: (C) the author(s), 2020. It is an open-access article distributed under the terms of the Creative Commons Attribution License (CC BY 4.0), which permits authors to retain ownership of the copyright for their content, and allow anyone to download, reuse, reprint, modify, distribute and/or copy the content as long as the original authors and source are cited.

How to cite this article: Nateson AK, Basavanayak SN, Srikanth S. A Study on Raised Serum LDH Level in Acute Intestinal Obstruction - A Marker of Bowel Gangrene. Acad. J Surg. 2020; 3(1):120-123.

DOI: dx.doi.org/10.47008/ajs/2020.3.1.26

Source of Support: Nil, Conflict of Interest: None declared. 